\section{Lessons from Madrid for next climate talks}

As the 2015 Paris climate summit approaches, it is worth noting that this month marks 20 years since the Madrid meeting at which the Intergovernmental Panel on Climate Change (IPCC) declared that "the balance of evidence suggests a discernible human influence on global climate".

Support for the 1995 IPCC statement came from the physical understanding of heat-trapping properties of greenhouse gases, observations of warming and comparisons of modelled and observed climate-change patterns (climate 'fingerprinting').

Criticism at the time stemmed from the paucity of fingerprint studies, the inadequate treatment of uncertainties, the focus on surface temperature, and poor quantification of natural climate noise and human-caused warming.

One lesson from Madrid is the importance of responding to justifiable criticism. Climate forensics have since identified human-caused temperature fingerprints from the stratosphere to the ocean depths, and in many variables other than temperature. It is routine to assess uncertainties in observed climate data and model simulations. The humancaused warming signal and the noise of natural climate variability are now better quantified. This signal has dominated since the mid-twentieth century.

We have also learned that global scientific understanding can emerge in less than 20 years from the noise of unreason and disinformation, and that one sentence can change the world. Benjamin D. Santer Lawrence Livermore National Laboratory, California, USA. santer1@llnl.gov

\section{Account for soil as natural capital}

Economics has an important connection with the health of soils (see, for example, P. Panagos et al. Nature 526, 195; 2015). Integrating information on soil resources with other measures of natural capital and economic activity remains one of the least developed areas of the United Nations System of Environmental Economic Accounting (SEEA).

The SEEA is a broad-scale monitoring tool that is gaining global momentum. It integrates environmental data with economic measures such as national income, stock markets and gross domestic product.

The potential of the SEEA and natural-capital accounting to support regional, national and global monitoring efforts is being rapidly recognized in forums such as the UN Sustainable Development Goals, the Aichi Biodiversity Targets and the development of a Natural Capital Protocol for businesses.

Accounting for soil resources makes a valuable contribution to this bigger picture.

Carl Obst University of

Melbourne, Australia.

cobst@unimelb.edu.au

\section{Drug pollution: Europe responds}

As directors of the Association of the European Self-Medication Industry (AESGP), the European Federation of Pharmaceutical Industries and Associations (EFPIA), and the European Generic and Biosimilar Medicines Association (EGA), respectively, we are committed to providing safe, efficient and high-quality medicines without releasing harmful components into the environment (see Nature 526, 164; 2015).

Effluents from drug manufacturing account for just $2 \%$ of the pharmaceuticals found in the environment in Europe (see go.nature.com/ovgyaa) because they are managed effectively (D. J. Caldwell et al. Environ. Toxicol. Chem. http:// doi.org/8xf; 2015). The industry has started to control drug pollution from other sources in response to legislation that governs all aspects of pharmaceutical operations. Monitoring continues even after medicines are on the market.

This is complemented by such initiatives as our Eco-PharmacoStewardship framework, a holistic environmental risk-management programme. We also run a joint medicines-disposal campaign on social media (www.medsdisposal. eu). And the iPIE project of the Innovative Medicines Initiative uses targeted assessment to identify the environmental risks of active drug contaminants.

Hubertus Cranz AESGP,

Brussels, Belgium.

Richard Bergström EFPIA,

Brussels, Belgium.

Adrian van den Hoven $E G A$, Brussels, Belgium.

richard.bergstrom@efpia.eu

\section{Drug pollution: industry responds}

The multinational drug company AstraZeneca has a long-standing commitment to proactively manage the environmental risks associated with drug manufacture and products in patient use (see Nature 526, 164; 2015). In the absence of legislation to control discharges from production sites, we have voluntarily devised concentration limits to ensure the safety of aquatic environments.

These environmental reference concentrations and maximum tolerable concentrations are derived using approaches similar to environmental quality standards developed under the Water Framework Directive (R. J. Murray-Smith et al. Integr. Envir. Assess. Manag. 8, 320-330; 2012). We have established them for all 42 of the company's active pharmaceutical ingredients.

Our global manufacturing sites and our key outsourced manufacturing partners meet these safe-discharge criteria. This should help to raise environmental standards across the industry. We completed 72 assessments of environmental reference concentrations with our supply chain in 2014.

We continuously collate published environmental data on all of our active pharmaceutical ingredients to keep our risk assessments and safe-discharge standards scientifically up to date (G. Holm et al. Drug Safety 36, 533-546; 2013).

Jason Snape, Wesley White AstraZeneca, Alderley Park, UK. jason.snape@astrazeneca.com Competing financial interests declared; see go.nature.com/uckxxf.

\section{Irked by naivety about policymaking}

We find William Sutherland and Mark Burgman's advice on the complex social processes between evidence and policy decisions to be naive at best, and antidemocratic at worst (see Nature 526, 317-318; 2015).

Policymakers are influenced by a much greater range of factors than are considered by the authors - including public opinion, inheritance of policies and institutional rules, finance, unpredictable events, and trust in actors (see also W. Pearce et al. Evid. Policy 10, 161-165; 2014).

In our view, the authors perpetuate negative stereotypes of policymakers and academics, when in fact many examples of productive collaborations and hybrid roles exist. Their edicts seem to undermine colleagues who mobilize knowledge for policy, and to reduce the intricate relationship between evidence and policy to a linear, technocratic process. As they themselves attest, giving advice to policymakers or academics that is not evidence-based could hamper the formation of useful collaborations.

Kathryn Oliver University of Oxford, UK.

Adam Wellstead Michigan

Technological University,

Houghton, USA.

Paul Cairney University of Stirling, UK.

kathryn.oliver@spi.ox.ac.uk 